\title{
A SOLUBILIDADE DOS COMPOSTOS IÔNICOS: COMO OS LICENCIANDOS EM QUÍMICA EXPLICAM O COMPORTAMENTO DO CLORETO DE PRATA?
}

Analice de Almeida Lima* Isauro Beltrán Núñez**

RESUMO: O trabalho objetivou analisar se licenciandos em Química fazem uso de um modelo teórico de ligação química para explicar a solubilidade de um composto químico. A investigação foi realizada ao longo de três anos, com 55 estudantes do curso de licenciatura em Química da UFRN, utilizando-se, para tanto, como instrumento de pesquis, a um questionário com questões abertas. A análise dos dados revelou que o modelo para as ligações iônicas não foi utilizado adequadamente para explicar o comportamento de um determinado composto iônico, o que indica limitações quanto aos saberes relativos a esse conteúdo no grupo investigado. Esses resultados evidenciam a importância da realização de discussões durante a formação inicial de professores acerca dos diferentes saberes que farão parte da prática docente. Palavras-chave: modelos, formação inicial, ligações químicas.

\section{THE SOLUBILITY OF IONIC COMPOUNDS: HOW UNDERGRADUATE CHEMISTRY STUDENTS EXPLAIN THE BEHAVIOR OF SILVER CHLORIDE?}

ABSTRACT: This study aimed to analyze whether future Chemistry teachers make use of a theoretical model of chemical bonding to explain the solubility of a chemical compound. The investigation was performed during a period of three years with 55 students from the UFRN Chemistry education program, using as a research tool a questionnaire with open questions. Data analysis revealed that the ionic bonding model was not used adequately to explain the behavior of a particular ionic compound, revealing limitations in the knowledge related to this subject in the investigated group. The results highlight the importance of fostering discussions during the initial teacher education about the different knowledges that will be part of their teaching practice.

Keywords: Models; Initial Teacher Education; Chemical Bonds. 


\section{INTRODUÇÃO}

A formação de professores de Ciências tem se configurado como um tema relevante nas pesquisas no campo da Didática das Ciências. Esse interesse relaciona-se com as preocupações da profissionalização da docência no tocante ao ensino das Ciências na educação básica.

O movimento de profissionalização fundamenta-se tanto na ação quanto nos conhecimentos especializados e representa um processo que, acima de tudo, busca a integração de saberes na atualização de competências. Nesse sentido, a profissionalização é entendida "como uma forma de representar a profissão como processo contínuo/descontínuo ao longo da história da docência” (NÚÑ̃Z; RAMALHO, 2008, p.1).

O paradigma da profissionalização da docência emerge em oposição ao paradigma da racionalidade técnica, o qual prevalece como referência para a formação docente. No paradigma da profissionalização, o professor é visto como um profissional que age com competência, mobilizando, de forma consciente, diferentes recursos (saberes, valores, atitudes, etc.) em sua prática docente. No contexto da profissionalização da docência, as pesquisas atinentes aos saberes profissionais constituem-se objeto de estudo sobre os professores e sua formação (RAMALHO, NÚÑEZ; GAUTHIER, 2003). Nessa direção, Gatti (2010, p.11) afirma que "não há consistência em uma profissionalização sem a constituição de uma base sólida de conhecimentos e formas de ação".

Nessa perspectiva, são importantes as discussões que ressaltam o papel dos diferentes tipos de modelos, que apresentaremos ao longo do texto, na construção do conhecimento químico, com isso, proporcionando aos licenciandos a compreensão das limitações dos modelos construídos na ciência, bem como da utilização desses modelos na explicação dos fenômenos químicos. Assim, defendemos que os saberes relacionados aos modelos no ensino de Química inserem-se na base de conhecimentos da profissão docente dessa área.

O uso de modelos e analogias como ferramentas para o ensino de Ciências Naturais também vem sendo investigado por nosso grupo de pesquisa, como é possível verificar nos trabalhos publicados por Lima e Núñez (2004a; 2004b; 2005) e Lima (2006; 2007). Nesses trabalhos, o objeto de estudo tem sido as ideias dos licenciandos em Química acerca do uso de modelos e analogias no ensino dessa ciência. Os dados revelam fragilidades tanto na compreensão relativa aos modelos e analogias quanto nas estratégias didáticas envolvidas no planejamento de atividades de ensino.

Sob tal contextualização, a presente investigação teve como objeto de estudo a forma como os licenciandos em Química utilizam os modelos de ligação iônica para explicar o comportamento de compostos iônicos. Especificamente, utilizamos o fato de o cloreto de prata ser insolúvel em água para analisar as explicações do grupo de licenciandos investigado. 
A solubilidade dos compostos iônicos: como os licenciandos

em química explicam o comportamento do cloreto de prata?

A escolha pertinente a ligações químicas deve-se ao fato de que, no ensino médio, esse tema relaciona-se a diferentes conceitos referentes à estrutura das substâncias, suas propriedades e aplicações, assim como a um conhecimento necessário para compreender os aspectos estruturais das transformações químicas.

\section{IMPORTÂNCIA DOS MODELOS NO ENSINO DE QUÍMICA: O CASO DAS LIGA- ÇÕES QUÍMICAS}

É essencial que, no ensino de Ciências, haja a compreensão de que o conhecimento científico é constituído por modelos que buscam representar a realidade. Por meio dos modelos elaborados, os cientistas formulam questões acerca do mundo; descrevem e interpretam fenômenos; elaboram e testam hipóteses; e fazem previsões.

Justi e Gilbert (2000) apontam para a importância de que, no ensino de Ciências, priorizem-se discussões que ressaltem a construção do conhecimento científico como modelo das ciências e como os contextos histórico, filosófico e tecnológico influenciam esse desenvolvimento, subsidiando, dessa forma, a compreensão da ciência e o aprendizado da mesma na educação científica escolar.

Em particular, no ensino de Química, essa é uma questão importante, pois, normalmente, ela é definida como uma ciência essencialmente experimental, e, por essa razão, os modelos não são geralmente destacados de forma explícita na construção do conhecimento químico, quando o próprio experimento é um procedimento para a construção de modelos.

Chassot (2003, p. 161) comenta que a necessidade de se usarem modelos é consequência de duas limitações:

[...] (i) construímos modelos na busca da facilitação de nossas interações com os entes Modelados. É através dos modelos, nas mais diferentes situações, que podemos fazer inferências e previsões de propriedades e (ii) os diferentes modelos podem ser modificados em função de novas leituras que se faz sobre a natureza.

É importante que façamos uma distinção entre os três tipos de modelos no ensino das Ciências Naturais:

- os modelos da ciência: são modelos reconhecidos e de consenso pela comunidade científica como parte de uma teoria. São o conhecimento científico como representação explícita;

- os modelos didáticos, de ensino ou pedagógicos (normalmente, elaborados por professores ou expressos nos livros didáticos): são modelos construídos para o ensino do conhecimento científico no contexto escolar. Estão relacionados não apenas com os objetos concretos, mas a todo o subsídio utilizado para ajudar a aprendizagem dos alunos, como ilustrações, objetos, gráficos, esquemas, analogias, etc. (JUSTI; GILBERT, 2000);

- os modelos dos alunos (modelos mentais): são representações que os alunos

Rev. Ensaio | Belo Horizonte | v. 14 | n. 01 | p.257-269 | jan-abr | 2012 
constroem sobre o objeto de estudo. Têm um caráter individual mediado pelo grupo e pelo contexto sociocultural. Esses modelos são expressões do tipo de compreensão que o aluno tem sobre o conhecimento escolar.

A aprendizagem pode ser compreendida como um processo de negociação desses modelos: do modelo da ciência e dos modelos dos alunos, mediados pelos modelos didáticos.

Enfatizamos neste trabalho o principal modelo científico usado no ensino médio para a ligação iônica. Para esse modelo, assumem-se as seguintes condições: - os íons são esferas perfeitas (não deformadas);

- a carga do íon (positiva ou negativa) está concentrada no centro;

- as interações entre as partículas são de natureza eletrostática, e pode ser usada a Lei de Coulomb para a explicação da formação do sólido cristalino (rede cristalina).

Entretanto, um aspecto a ser salientado é o fato de que as propriedades dos compostos iônicos são determinadas pela polarização mútua dos íons que entram na composição da rede cristalina, que afasta o composto das previsões do modelo de ligação iônica anteriormente exposto. A polarização (deformação das camadas eletrônicas) de um íon é indicada pelo deslocamento relativo do núcleo e dos elétrons das camadas eletrônicas externas que o rodeiam sob a ação do campo elétrico do íon vizinho. Dessa forma, a polarização conduz à diminuição do grau iônico da ligação, e, consequentemente, há um aumento do caráter covalente. Entendemos como essencial a compreensão dessa questão para que, na abordagem das ligações iônicas, o professor possa propor modelos didáticos que subsidiem a aprendizagem desse conteúdo por parte dos alunos.

Outro fator importante está relacionado ao tamanho dos íons. A esse respeito, Atkins e Jones (2001) inferem que um ânion pode ser altamente polarizável se for grande. Neste caso, o núcleo do íon exerce pouca influência sobre seus elétrons mais externos, pois estes estão mais distantes. Em relação ao cátion, observamos que este terá um alto poder polarizante se for pequeno e altamente carregado, visto que um raio pequeno significa que o centro de cargas de um cátion altamente carregado pode ser encontrado muito perto do ânion, onde exerce uma forte atração sobre os elétrons do ânion. Portanto, compostos constituídos de um cátion, pequeno e altamente carregado, e de um ânion, grande e polarizável, tendem a ter ligações com considerável caráter covalente.

Na literatura (PETERSON; TREAGUST, 1989; PETERSON; TREAGUST; GARNET'T, 1989; DE POSADA, 1999; RIBOLDI; PLIEGO; ODETI, 2004; CARVALHO; JUSTI, 2005; MENDONÇA; JUSTI, 2005; LIMA; COSTA; NÚÑEZ, 2005), temos encontrado investigações que buscam revelar as dificuldades que permeiam a aprendizagem do conteúdo ligações químicas, ratificando, dessa forma, a importância de pesquisas que abordem esse conteúdo.

Peterson e Treagust (1989) e Peterson, Treagust e Garnett (1989) investigaram as ideias de estudantes acerca das ligações covalentes e de suas estruturas.

Os resultados desses estudos revelaram que $23 \%$ dos alunos não conside- 
A solubilidade dos compostos iônicos: como os licenciandos

em química explicam o comportamento do cloreto de prata?

ravam a influência da eletronegatividade e compartilhamento desigual do par de elétrons na ligação covalente polar; $27 \%$ admitiam que a polaridade é influenciada pela geometria das moléculas; $23 \%$ confundiam forças intermoleculares com as forças intramoleculares, enquanto $33 \%$ não consideravam a existência de forças intermoleculares na rede covalente.

A investigação realizada por De Posada (1999) junto a estudantes teve como objetivo analisar, entre outras questões, as concepções mais características em relação às substâncias moleculares e iônicas e como os estudantes utilizavam conhecimentos relacionados às ligações químicas para interpretar fórmulas químicas encontradas em seus textos e explicações de sala de aula. Os resultados dessa pesquisa sinalizaram que as noções do mundo macroscópico foram aplicadas no nível atômico, embora tenham apontado que explicações nesse sentido diminuem à medida que o estudo em Química avança. A natureza da ligação covalente não foi compreendida de forma adequada pelos alunos, em diferentes graus de escolaridade. A existência de forças intermoleculares é outra questão pouco interiorizada pelos estudantes em relação à ligação covalente e, portanto, menos utilizada em suas explicações.

Riboldi, Pliego e Odeti (2004), em pesquisa realizada com estudantes universitários, destacaram algumas concepções alternativas relacionadas a ligações químicas, as quais indicamos a seguir:

- átomos de um mesmo elemento químico unem-se por ligação iônica; - átomos de elementos diferentes unem-se apenas por ligação iônica;

- a ligação iônica é mais forte que a ligação covalente; - a ligação química não é vista como um processo espontâneo;

- ao formarem as moléculas, os átomos permanecem sem modificar suas estruturas, como se estivessem apenas próximos uns dos outros;

- existem moléculas de substâncias iônicas;

- a causa da ligação iônica se deve ao fato dos átomos completarem seus octetos.

Uma consideração importante feita pelos autores é de que não há uma significativa mudança das concepções alternativas no decorrer do ensino superior, o que aponta para fragilidades na abordagem desse conteúdo, nesse nível de ensino.

Nas pesquisas conduzidas por De Posada (1999) e Riboldi, Pliego e Odeti (2004), há um consenso no tocante às fragilidades que os estudantes estabelecem entre a estrutura ou representação de uma substância e seu tipo de ligação química. Essa questão, de acordo com Riboldi, Pliego e Odeti (2004), pode ser associada ao fato de que, no ensino de Química, quando se faz referência a uma substância e a sua representação, recorre-se normalmente a sua fórmula química, e não à estrutura espacial característica dessa substância.

Mendonça e Justi (2005) e Carvalho e Justi (2005), em seus estudos, buscaram atrelar o conteúdo ligações químicas aos modelos de ensino e àqueles construídos pelos alunos durante o processo de ensino-aprendizagem em Química.

Assim, Carvalho e Justi (2005) procuraram, em uma investigação junto a 
estudantes do ensino médio, identificar as principais dificuldades desses alunos em construírem um modelo em relação à ligação metálica a partir da analogia do "mar de elétrons". A análise dos dados obtidos na pesquisa indicou que a utilização da analogia do "mar de elétrons" tem conduzido os alunos a inferências errôneas, por não enfatizar aspectos como a formação do arranjo tridimensional dos cátions e o fato de que esse arranjo difere, entre os metais, a existência de forças atrativas entre cátions e elétrons como responsável pela união desses e estabilidade na estrutura e a existência de forças de repulsão entre os cátions e elétrons, bem como a importância dessas forças para a definição e manutenção da estrutura tridimensional.

Mendonça e Justi (2005), por sua vez, investigaram um processo de ensino de ligações químicas, no ensino médio, planejado a partir da consideração de que a construção de modelos desempenha um processo central na aquisição do conhecimento, seja na ciência, seja no ambiente escolar. A revisão da literatura realizada pelas autoras sinaliza algumas concepções alternativas dos estudantes relacionadas a esse conteúdo, tais como:

- utilização indiscriminada de termos antropomórficos e aplicações animistas da regra do octeto, como na alegação de que os átomos têm a tendência a perder ou ganhar elétrons para que completem seus octetos;

- concepção de pares de íons como moléculas de uma substância iônica, fato que dificulta que os alunos reconheçam e compreendam um modelo para a estrutura de um composto iônico;

- dificuldades em se explicarem as propriedades dos compostos iônicos, visto que não há clareza de um modelo para esse tipo de composto.

A sequência de ensino adotada pelas autoras contemplou a construção de modelos considerando o processo de elaboração, expressão, discussão e reformulação dos modelos por parte dos alunos. O questionário aplicado depois da sequência evidenciou que a maioria dos alunos não apresentou as principais concepções alternativas descritas na literatura. Os alunos conceberam a ligação iônica como uma atração eletrostática. No tocante à formação de redes nos compostos iônicos, a maioria desses estudantes relacionou coerentemente a estrutura em rede com as propriedades dos compostos iônicos.

As investigações anteriormente descritas ratificam a necessidade de estudos que abordem o tema ligações químicas como subsídio à profissionalização docente, pois se revela fundamental à construção de uma base sólida de conhecimentos (GATTI, 2010).

\section{METODOLOGIA}

\section{Os licenciandos participantes da pesquisa}

O contexto investigado foi a Universidade Federal do Rio Grande do Norte, tendo-se como sujeitos da pesquisa 55 licenciandos em Química, de três 
A solubilidade dos compostos iônicos: como os licenciandos em química explicam o comportamento do cloreto de prata?

turmas de anos diferentes (2004, 2005 e 2007), na disciplina Prática de Ensino de Química, que, na estrutura curricular, era a última disciplina do curso de licenciatura em Química. No ano de 2004, investigaram-se 22 licenciandos; no ano de 2005, 18 licenciandos; e, no ano de 2007, 15 licenciandos, os quais denominamos A1-A22 (turma de 2004), B1-B18 (turma de 2005) e C1-C15 (turma 2007). O grupo investigado era constituído de 24 pessoas do sexo feminino e 31 do sexo masculino. Do total de participantes, $85,45 \%$ trabalhavam, o que, de certa forma, dificultava uma dedicação maior às atividades acadêmicas, 56,36\% dos estudantes investigados lecionavam Química no ensino médio, e 74,20\% já tinham lecionado Química nos níveis fundamental e médio.

\section{Instrumento utilizado na pesquisa}

O instrumento de pesquisa utilizado continha um questionário com duas perguntas abertas (Quadro 1) para que os licenciandos investigados apresentassem explicações relativas à solubilidade de uma substância iônica (Cloreto de Prata - AgCl) em água. No ano de 2004, entretanto, os licenciandos tinham de responder apenas à questão 1, e, a partir da análise das respostas a essa pergunta , propusemos a questão 2, a qual nos permitiu uma melhor compreensão dos modelos mobilizados pelos licenciandos para explicar a solubilidade do $\mathrm{AgCl}$.

A opção pelo instrumento de pesquisa deu-se pela limitação de tempo para um contato individual com os licenciandos, mas propiciou aos licenciandos maior reflexão para apresentarem suas considerações acerca das questões levantadas no questionário.

\section{Quadro 1- Questões analisadas referentes aos modelos na ciência e da ligação iônica}

\section{Análise dos dados}

\footnotetext{
1- A ligação iônica ocorre entre um metal e um não metal, e o composto resultante é mantido pela atração existente entre os íons formados. Uma das características observadas, na maioria desses compostos, como o cloreto de sódio, é a solubilidade em água à temperatura ambiente $\left(25^{\circ} \mathrm{C}\right)$.

Como você poderia explicar o fato de o cloreto de prata $(\mathrm{AgCl})$, composto formado por um metal e um não metal, ser insolúvel em água?

2- Represente, mediante um esquema, a estrutura do $\mathrm{AgCl}$ sólido que justifique sua pouca solubilidade em água nessas condições.

Represente um esquema para a estrutura $\mathrm{NaCl}$ e compare em relação ao $\mathrm{AgCl}$. Justifique.
}

Para análise das respostas tomou-se como referência o modelo de ligação iônica já descrito, bem como o efeito da polarização. As respostas fornecidas pelos licenciandos foram analisadas, agrupadas em categorias, apresentadas em tabelas e discutidas a partir do referencial teórico apresentado em nossa discussão. 


\section{RESULTADOS E DISCUSSÃO}

Para análise da questão 1 (Quadro 1), admitimos que a insolubilidade do cloreto de prata em água, a $25^{\circ} \mathrm{C}$, estaria relacionada às características dos íons $\mathrm{Ag}^{+}$e $\mathrm{Cl}^{-}$(a deformação devido ao efeito da polarização), o que levaria a uma ligação com forte caráter covalente (afastando-se do modelo de ligação iônica), e que, por sua vez, a energia de solvatação não seria suficiente para quebrar as forças do retículo cristalino do referido composto, explicando-se, dessa maneira, a insolubilidade desse composto nas condições normais em água.

A partir das respostas dos licenciandos à questão 1, inicialmente, analisamos se houve utilização do modelo para se explicar o comportamento do cloreto de prata (Tabela 1). Os dados apresentados na tabela 1 sinalizam para o fato de que os licenciandos investigados não utilizam, de modo adequado, o modelo de ligação iônica para explicar a insolubilidade do $\mathrm{AgCl}$ em água. Isso ratifica a revisão da literatura, realizada por Mendonça e Justi (2005), que indica dificuldades, da parte dos estudantes pesquisados, para explicar as propriedades dos compostos iônicos, visto que não há uma clareza de um modelo para esse tipo de compostos.

Tabela 1- Relação da solubilidade com o AgCl(\%).

\begin{tabular}{|l|l|l|l|}
\hline \multicolumn{1}{|c|}{ Categoria de respostas } & \multicolumn{1}{|c|}{2004} & 2005 & 2007 \\
\hline $\begin{array}{l}\text { 1- Utiliza o modelo para explicar } \\
\text { o comportamento da substância. }\end{array}$ & 0,00 & 0,00 & 0,00 \\
\hline $\begin{array}{l}\text { 2.1- Explicação envolve o efeito } \\
\text { de polarização dos íns. }\end{array}$ & - & - & 20,00 \\
\hline $\begin{array}{l}\text { 2.2- Explicação relacionada com } \\
\text { a energia de solvatação. }\end{array}$ & 9,09 & 16,67 & - \\
\hline $\begin{array}{l}\text { 2.3- Explicação envolve ideias ac- } \\
\text { erca do retículo cristalino e os } \\
\text { tamanhos dos íns. }\end{array}$ & 4,54 & 11,11 & - \\
\hline $\begin{array}{l}\text { 2.4- Explicação aponta que não se } \\
\text { pode generalizar as explicaç̃̃es } \\
\text { para todos os compostos. }\end{array}$ & 9,09 & - & 13,34 \\
\hline $\begin{array}{l}\text { 2.5- Explicação fornecida está } \\
\text { relacionada à interação existente } \\
\text { entre os íns Ag+e Cl- e entre } 0 \\
\text { Na+e o Cl-. }\end{array}$ & 36,36 & 55,56 & 40,00 \\
\hline $\begin{array}{l}\text { 2.6- Explicação fornecida não tem } \\
\text { elementos que respondam à per- } \\
\text { gunta realizada. }\end{array}$ & 27,27 & 55,56 & 26.67 \\
\hline 2.7- Não respondeu. & 13,64 & 5,56 & - \\
\hline
\end{tabular}

As respostas dos licenciandos, apesar de não apresentarem explicações que articulassem os elementos que consideramos para essa questão, foram cate- 
A solubilidade dos compostos iônicos: como os licenciandos em química explicam o comportamento do cloreto de prata?

gorizadas, emergindo sete subcategorias que foram apresentadas na tabela 1 . No ano de 2005, as respostas dos licenciandos envolveram mais de uma subcategoria. Dessa forma, apresentamos, na tabela 1, o número de respostas dos licenciandos investigados para cada subcategoria apresentada. Pudemos observar que algumas dessas subcategorias sinalizaram elementos importantes para a explicação da insolubilidade do cloreto de prata. Contudo, esses elementos apareceram de maneira isolada, não permitindo, dessa forma, que as explicações para tal comportamento fossem bem estruturadas. Esse é o caso das subcategorias 2.1, 2.2 e 2.3 (Tabela 1), em que os licenciandos utilizaram em suas explicações elementos como: o efeito da polarização dos íons; a energia de solvatação; retículo cristalino e tamanho dos íons.

O efeito de polarização dos íons (subcategoria 2.1) foi apontado em $20 \%$ das respostas dos licenciandos investigados, no ano de 2007. Esse é um dado interessante, visto que a polarização dos íons prata e sódio é um fator importante para que se explique a deformação dos íons, levando à alteração na rede cristalina do cloreto de prata e, assim, influenciando na solubilidade desse composto.

A baixa energia de solvatação (subcategoria 2.2) para que fossem quebradas as interações no retículo cristalino do $\mathrm{AgCl}$ foi indicada em 9,09\% das respostas dos licenciandos, em 2004; e, em 16,67\% das respostas dos licenciandos, no ano de 2005. Essa é uma questão que também se verificou na explicação da insolubidade do $\mathrm{AgCl}$, mas esses licenciandos não explicam o porquê de o cloreto de prata apresentar uma estrutura em que não há essa solvatação.

Considerações relativas ao retículo cristalino e aos tamanhos dos íons (subcategoria 2.3) foram evidenciadas em 4,54\% das respostas dos licenciandos no ano de 2004; e, em 11,11\% das respostas dos licenciandos, no ano de 2005, sinalizando elementos importantes para a explicação da insolubilidade do cloreto de prata.

Apesar de não destacarem os elementos já mencionados para explicar essa questão, 9,09\% das respostas dos licenciandos no ano de 2004 apontam a ideia de que não se podem generalizar as explicações para todos os compostos (subcategoria 2.4). Assim, é possível indicar, em uma análise inicial, que o conhecimento científico, como forma de representar uma parte da realidade, faz recortes ao estudar determinado fenômeno e que, por essa razão, algumas questões não podem ser explicadas como um regra geral.

Como podemos observar na tabela 1 , a maioria das respostas fornecidas pelos licenciandos convergiu às subcategorias 2.5 e 2.6. Na subcategoria 2.5, as respostas referiram-se ao fato das interações serem diferentes entre os íons no $\mathrm{NaCl}$ e no $\mathrm{AgCl}$, mas não indicaram que fatores levariam a essas diferenças. Já na subcategoria 2.6, os licenciandos não utilizaram, em suas explicações, elementos que consideramos para a análise dessa questão. Algumas dessas respostas podem ser observadas nos depoimentos dos licenciandos A17 e C3. 
Resposta de A17

"Um dos fatores que poderia estar relacionado seria o meio em que a reação foi produzida, o raio atômico, a distribuição eletrônica dos átomos".

Resposta de C3

"Devido à baixa reatividade da prata".

Nos anos de 2005 e 2007, foi solicitado que os licenciandos representassem por um esquema as causas que podem explicar as diferenças de solubilidades. Os resultados são apresentados na tabela 2.

Tabela 2 - Representação esquemática para justificar a pouca solubilidade do $\mathrm{AgCl}$ em água (\%).

\begin{tabular}{|l|l|l|}
\hline \multicolumn{1}{|c|}{ Categoria de respostas } & 2005 (\%) & 2007 (\%) \\
\hline $\begin{array}{l}\text { 1- Representa em função do modelo } \\
\text { de ligação iônica. }\end{array}$ & 5,56 & - \\
\hline $\begin{array}{l}\text { 2- Não representa em função do modelo } \\
\text { de ligação iônica. }\end{array}$ & 94,44 & 100 \\
\hline 2.1- Utiliza fórmulas para a representação. & 61,11 & 33,33 \\
\hline $\begin{array}{l}\text { 2.2- Utiliza a representação dos retículos } \\
\text { cristalinos sem a deformação dos íons. }\end{array}$ & 11,11 & - \\
\hline Não respondeu. & 11,11 & 66,67 \\
\hline
\end{tabular}

$\mathrm{Na}$ tabela 3, elencamos que apenas 5,56\% dos licenciandos, no ano de 2005, explicaram o comportamento $\mathrm{AgCl}$ em função do modelo da ligação iônica, indicando que, devido à deformação dos íons no $\mathrm{AgCl}$, o retículo cristalino seria diferente do $\mathrm{NaCl}$, explicando-se, assim, a diferença de solubilidade entre esses dois compostos iônicos. Ainda em 2005, a maioria dos licenciandos (61,11\%) utilizou fórmulas e equações para explicar a insolubilidade do $\mathrm{AgCl}$ em água. Em 2007, nenhum dos licenciandos investigados indicou representações para os compostos de modo a explicar as diferenças de solubilidade, 33,33\% desses licenciandos utilizaram fórmulas para representação dos dois compostos e $66,67 \%$ não responderam a essa questão.

Essa dificuldade em representar espacialmente os compostos iônicos valida as considerações de Riboldi, Pliego e Odeti (2004) no sentido de que, no ensino de Química, quando se faz referência a uma substância e a sua representação, recorre-se normalmente a sua fórmula química, e não à estrutura espacial característica dessa substância.

A seguir, nas figuras 1 e 2, ilustramos as representações feitas por dois li- 
A solubilidade dos compostos iônicos: como os licenciandos em química explicam o comportamento do cloreto de prata?

cenciandos para explicar as diferenças de solubilidade do cloreto de sódio e do cloreto de prata.

Figura 1- Representação de um licenciando sobre a diferença de solubilidade
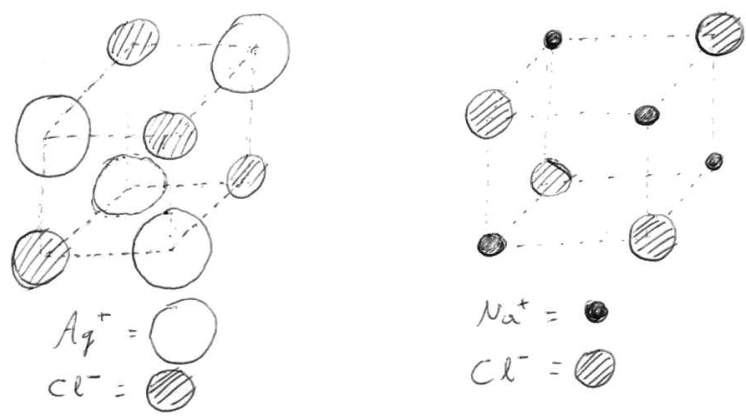

Fonte: Dados da Pesquisa

Figura 2- Representação de um licenciando sobre as diferenças de solubilidade
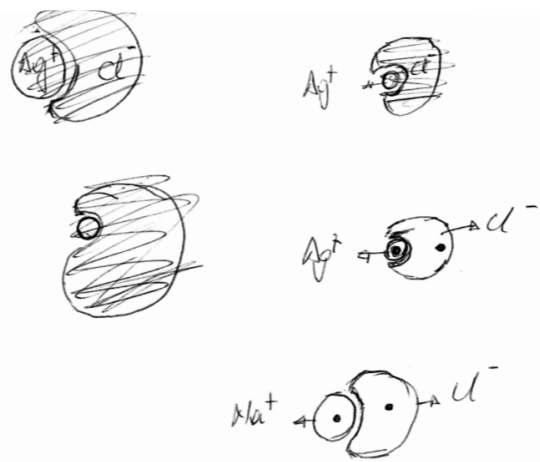

Fonte: Dados da Pesquisa

Essas ilustrações permitem-nos apontar que, na figura 1, há uma tentativa de se explicar o comportamento dos compostos em função do retículo cristalino, que, no caso do $\mathrm{AgCl}$, dificultaria a solvatação. Já na figura 2, o licenciando procura representar o efeito da polarização para explicar a diferença de solubilidade entre os compostos. 


\section{CONCLUSÕES}

Os resultados desta pesquisa apontaram limitações na explicação dos licenciandos investigados em relação à insolubilidade do cloreto de prata em água. Embora certos elementos que expliquem o comportamento desse composto iônico tenham sido citados por alguns licenciandos, como o efeito de polarização dos íons, a energia de solvatação, etc., não se observaram explicações que envolvessem tanto o modelo científico apresentado neste trabalho quanto o efeito de polarização dos íons.

Os licenciandos investigados também apresentaram dificuldades em representar espacialmente os compostos iônicos de modo a explicar as propriedades desses compostos. A rede cristalina na estrutura dos compostos iônicos não foi considerada nessa representação, pela maioria dos licenciandos investigados.

A dificuldade em utilizar o modelo de ligação iônica para explicar as propriedades dos compostos iônicos confirma a importância de que, durante o processo formativo inicial, o conhecimento do conteúdo seja abordado de maneira consistente por parte dos formadores, propiciando, dessa maneira, elementos ao futuro professor para que, na sua prática profissional, possa tornar esse conhecimento acessível aos seus alunos. Contemplar discussões e reflexões nesse sentido, durante a formação inicial de professores de Química, constitui um subsídio à profissionalização à medida que possibilita a construção de saberes que compõem a prática docente.

\section{BIBLIOGRAFIA}

ATKINS, P.; JONES, L. Princípios de Química: questionando a vida moderna e o meio ambiente. Porto Alegre: Bookman, 2001.

CARVALHO, N. B.; JUSTI, R. S. Dificuldades dos alunos na construção de modelos mentais de ligação metálica baseados na analogia do "mar de elétrons". In: ENCONTRO NACIONAL DE PESQUISA EM EDUCAÇÃO EM CIÊNCIAS, 5., 2005, Bauru. Anais... Bauru: ABRAPEC, 2005. 1 CD-ROM.

CHASSOT, A. Educação conSciência. Santa Cruz do Sul: EDUNISC, 2003.

DE POSADA, J. M. Concepciones de los alumnos sobre el enlace químico antes, durante y después de la enseñanza formal. Problemas de aprendizagen. Enseñanza de las Ciencias, v.17, n. 2, p. 227-245, 1999.

GATTI, B. Formação de professores no Brasil: características e problemas. Educação e Sociedade, v. 31, n. 113, p. 1355-1379, 2010.

JUSTI, R.; GILBERT. History and philosophy of science through models: some challengs in the case "of atom". Internacional Journal Science Education, v. 22, n. 9, p. 993-1009, 2000. LIMA, A. A. Obstáculos à compreensão do modelo de ligação iônica: uma investigação 
A solubilidade dos compostos iônicos: como os licenciandos em química explicam o comportamento do cloreto de prata?

junto a professores do ensino médio de química e em livros didáticos de química. In: ENCONTRO NACIONAL DE DIDÁTICA E PRÁTICA DE ENSINO, 13., 2006, Recife. Anais... Recife: UFPE, 2006. 1 CD-ROM.

- O uso de modelos no ensino de química: uma investigação acerca dos saberes construídos durante a formação inicial de professores de Química da UFRN. 2007. 264 f. Tese (Doutorado em Educação) - Centro de Ciências Sociais e Aplicadas, Universidade Federal do Rio Grande do Norte, Natal, 2007.

LIMA, A. A.; NÚÑEZ, I. B. As analogias no ensino de química: uma investigação dos saberes na formação inicial de professores. In ENCONTRO NACIONAL DE DIDÁtICA E PRÁTICA DE ENSINO, 12., Porto Alegre. Anais.. Porto Alegre: UFRGS, 2004a. 1 CD-ROM.

. Aprendizagem por modelos utilizando modelos e analogias. In: NÚÑEZ, I.; RAMALHO, B.(Org). Fundamentos do ensino-aprendizagem das ciências naturais e da matemática: o novo ensino médio. Porto Alegre: Sulina, 2004b. p.245-264.

. O que pensa um grupo de licenciandos sobre o uso de modelos e analogias no ensino de química? In: ENCONTRO DE PESQUISA EDUCACIONAL DO NORTE E NORDESTE, 17., Belém. Anais... Belém: UFPA, 2005. 1 CD-ROM.

LIMA, A. A.; NÚÑEZ, I. B.; SOARES, W. C. Os saberes docentes relativos aos modelos da ciência como ferramenta do conhecimento pedagógico do conteúdo: o caso de futuros licenciados em química. In: ENCONTRO NACIONAL DE PESQUISA EM EDUCAÇÃO EM CIÊNCIAS, 5., 2005, Bauru. Anais... Bauru: ABRAPEC, 2005. 1 CD-ROM. MENDONÇA, P. C. C.; JUSTI, R. S. Construção de modelos de ligação iônica. In: ENCONTRO NACIONAL DE PESQUISA EM EDUCAÇÃO EM CIÊNCIAS, 5., 2005, Bauru. Anais... Bauru: ABRAPEC, 2005. 1 CD-ROM.

NÚÑEZ, I.; RAMALHO, B. A profissionalização da docência: um olhar a partir das representações dos professores do ensino fundamental. Revista Iberoamericana de Educación, n. 46, v.9, 2008. OEI. Disponível em: <http://www.rieoei.org/2504.htm.>. Acesso em: $27 / 10 / 2008$.

PETTERSON, R. F.; TREAGUST, D. F. Grade-12 student's misconceptions of covalent bonding and structure. Journal of Chemical Education, v. 66, n. 6, p. 459-460, 1989.

PETTERSON, R. F.; TREAGUST, D. F.; GARNETT, P. Development and application of a diagnostic instrument to evaluate grade- 11 and grade- 12 student's concepts of covalent bonding and structure following a course of instruction. Journal or Research in Science Teaching, v. 24, n. 4, p. 301-314, 1989.

RAMALHO, B. L.; NÚÑEZ, I.; GAUTHIER, C. Formar o professor, profissionalizar o ensino - perspectivas e desafios. Porto Alegre: Sulina, 2003.

RIBOLDI, L.; PLIEGO, O.; ODETTTI, H. El enlace químico: una conceptualización poco comprendida. Enseñanza de las Ciencias, v. 22, n.2, p. 195-212, 2004.

Data de recebimento: 08/08/2011

Data de aprovação: 22/10/2011

Data da versão final: 16/12/2011

Rev. Ensaio | Belo Horizonte | v. 14 | n. 01 | p.257-269 | jan-abr | 2012 